THURSDAY, JULY 19, I888.

\section{THE CHOICE OF A CHEMIST TO THE NAVY.}

SIR HENRY ROSCOE'S watchful regard of the true $S$ interests of science was evidenced by his recent question in the House to the First Lord of the Admiralty, whether, in consequence of the resignation of Dr. Debus of the Professorship of Chemistry in the Royal Naval School at Greenwich, it was pronosed to reduce the status of this post to a lectureship ; and if so, whether he would take into consideration the inexpediency of this step being taken, in view of the importance to naval officers of a knowledge of this science, and of the necessity that in the Government Naval School the post in question should be filled by a gentleman of the highest possible scientific position and attainments.

Lord G. Hamilton is reported to have replied that the resignation of Dr. Debus, Professor of Chemistry at the Royal Naval College, had only just been received by the Admiralty, and therefore it would be premature to make any statement as to the manner in which it may be thought 'desirable to fill the vacancy so caused. The policy of the Admiralty was always to inquire into the circumstances of any appointment of this kind that may fall vacant, with the view of adjusting the salary to the requirements of the day.

It must be obvious that this statement savours most strongly of officialism, and that it affords no information whatever with regard to the views and intentions of the Admiralty. We have alreddy clearly indicated what are the requirements of the day, and Sir Henry Roscoe has given emphasis to our views; but it is more than probable that unless attention be again directed to the importance of the issues involved in the appointment of a chemist to the Navy the course of action indicated in our previous article as likely to be followed will inevitably be adopted.

We therefore without hesitation again urge that in a case of this kind only one course can be adopted with safety by the Admiralty, if the interests of the nation are to be considered-that course is to engage the services of the best man available. No candidate's claims should be considered unless it can be shown that he is a trained chemist, and has been actively engaged in the pursuit of new knowledge ; and unless it appear probable that he is enthusiastic and single-minded enough to continue to interest himself in research work and to lead his senior pupils to engage in research. We are fully aware that in imposing this standard we are demanding higher qualifications than many may consider necessary; that some may even think that nothing more is required at Greenwich than one who will teach young midshipmen the elements of chemistry and simple analysis fairly well; but to this we demur most emphatically, believing it to be incontestable that the science of chemistry may minister directly and indirectly in so many ways to the wants of our Navy that it is essential to give it the highest possible footing in the course of study at a naval college.

In the recently published life of W. E. Forster, a fragment of conversation at a dinner party preserved by Mrs. Forster is recorded which will be aptly quoted here. "Mr. —— said that — was always going about asking people what was the ideal towards which they VOL. Xxxill.-NO. 977. were working, and there was a laugh at the notion. But my husband did not join in it, saying that, for his part, if he was not constantly thinking of the ideal which he was working up to, he should not be able to get on at all " We venture to think that the infertility of British chemists and the inferior position which chemistry holds in this country, especially at our two great universities, as well as our failure to excel in those inclustries in which chemistry plays an important part, are due to the absence of an ideal among our chemists generally in any way approaching to that which has long obtained in Germany, where no higher grade appointment can be bestowed except on a man who is master of his subject, and not a past-master eren but an active worker; and it is the absence of any such ideal which in cases like the present renders it possible for the authorities to entertain the suggestion of reducing the status of the post at Greenwich.

We believe that a master chemist is required at Greenwich for a variety of reasons. Firstly, as a matter of national honour ; secondly, because, as we have already said, the subject must be taught technically, i.e. with direct reference to the knowledge and requirements of the students; thirdly, because the students are not only young beginners, but are of all ages, including many men of ripe experience, and it is scarcely necessary to remark that no one who is not a thorough chemist can possibly gain the sympathies of this latter class; and, lastly, because no one who is not himself actively engaged in research will remain au courant with the progress of knowledge, and will be able to select and incorporate into his teaching important new facts, thus avoiding the otherwise inevitable tendency to teach in a stereotyped and bookish fashion from year to year.

The proper man being found, he should be told at the outset that it is expected that when engaged in investigation he will devote his attention primarily to problems of importance in the Navy; a short intercourse with men versed in naval affairs and requirements would soon furnish an active-minded chemist with more than sufficient subject-matter meriting attentive study. It is more than probable that if a good example were set, and a spirit of enthusiasm kindled among the students, officers who had been led to take a real interest in chemistry would be willing, in the intervals of enforced inactivity when they were not on service, to devote themselves to research; and if but moderate encouragement were given to such men, we can conceive that Greenwich at no distant date might become an important school of naval research.

Unfortunately it is only too obvious that the public are slow to heed the repeated warnings of experts that our competitors in commerce are outrunning us largely because of their readiness to avail themselves of the aid which science can afford to industry. The evidence that foreign Governments are more anxious than is ours to make every possible use of science in the service of the Army and Navy is also growing daily ; but we are confident that in the present instance the danger of the retrograde action which appears to have been contemplated having been pointed out. the naval authorities will not allow themselves to be guided by shortsighted advisers, and will no longer countenance any change which does not enhance their opportunities of receiving aid from so all-important a branch of science as chemistry. 